\title{
Personalized Reform of Computer Education Based on Network Teaching Mode
}

\author{
Zhangrong $\mathrm{Hu}^{1}, \mathrm{Ke} \mathrm{He}^{1}$ \\ ${ }^{1}$ China West Normal University
}

\begin{abstract}
The current education and teaching reforms are constantly creating a "student-centered, teacherled" teaching model, and promote the development of education and teaching in a personalized direction. Therefore, cultivating and improving the learning ability of college students through personalized network teaching mode has become one of the hot issues in the current education and teaching reform and development. The purpose of this paper is to study the personalized reform of computer education based on the network teaching model, based on the constructivist learning theory, combined with the research results of artificial intelligence, to the knowledge representation, student personality evaluation and teaching strategy decisionmaking in the personalized computer-assisted teaching system research and exploration have been carried out on other issues, forming a network teaching system with certain intelligence. In computer teaching, "Configuring Computer" is used as the learning theme to compare the advantages and disadvantages of personalized network teaching and traditional network teaching. A detailed analysis of the two inquiry learning and a more in-depth reflection were carried out. The experimental results show that the students' inquiry cooperation ability and the quality of works in personalized online teaching have been improved to varying degrees. On the whole, the ratio of excellent to good in learning evaluation increased, and the ratio of medium to poor decreased, and the quality of multimedia works of more than $13 \%$ of students improved to excellent. The two teachings were carried out smoothly and basically achieved the expected goals proposed in this article.
\end{abstract}

\section{Introduction}

In today's society, with the increasing development of information technology, people are required to have the ability to learn for life, and to make themselves develop freely and comprehensively in continuous learning [1]. Due to the limitation of time and space, the learning mode under the network environment has undoubtedly become the preferred learning mode for learners in the learning process. Personalized learning mode is a very important learning mode in current online education [2]. This mode is a full manifestation of the superiority of online learning [3-4]. The application of personalized learning mode in online learning has changed the importance of learning goals, learning content, learning methods and learning models [5]. Strengthening the research on the personalized learning mode in online education has very important practical significance for the reform and development of online education [6-7].

Deepening the teaching reform can make the curriculum more reasonable, the teaching content is more scientific, and the teaching mode is more effective [8]. Mbise K S explores the theory of complexity and demonstrates how the pedagogical implications of complexity lead to the understanding of new models of computer learning and teaching. A new conceptual enduser computer education model was proposed, which was developed by a three-year action research initiative with pre-service teachers [9]. Gorbunova I B describes a metacognitive computer education method aimed at training lifelong computer learners. A series of theories, including social cognition theory, attribution theory, learning style theory, and explaining how metacognitive methods affect the attitudes, values and beliefs of computer learners [10].

This article introduces the status quo of the network subject inquiry learning mode in more detail, designs a network subject inquiry learning case based on "Configuring Computer", and initially explores a personalized network inquiry approach suitable for computer teaching through practice. Explains the theoretical research of the personalized computer-assisted teaching system model under the network environment, and the research on the personalized learning theory under the network environment, mainly from the diagnosis of student learning and the division of similar groups, etc., to explain the support for the personalized learning model theoretical basis. Combining the practice of this research in the university's online education and teaching, explore and research these basic theories that support personalized learning. It is hoped that these theories can better guide the 
practice of personalized learning mode in the network environment.

\section{Research on Personalized Reform of Computer Education Based on Network Teaching Mode}

\subsection{Personalized Computer-assisted Teaching System Model}

The ICAI system should have the following functions: have sufficient learning resources, that is, knowledge of a certain subject or field; be able to evaluate and record the learning situation of students through the learning process, analyze the characteristics of students and problems in learning; according to the characteristics of students choose suitable learning resources and teaching methods. Therefore, the basic elements of the ICAI teaching model should include: domain knowledge base, student model and teacher model.

\subsection{Diagnosis of Students' Learning Situation and Division of Similar Groups}

The course materials are stored in the course database. For most courses, the course materials are difficult and easy. Here we design a method based on the learner's cooperative voting mechanism to automatically adjust the difficulty parameters of the course materials.

The difficulty of rating the $j$-th course material based on the students' cooperative voting:

$$
\operatorname{Dj}(\text { voting })=\sum_{\mathrm{i}=1}^{5} \frac{\mathrm{n}_{\mathrm{ij}}}{\mathrm{N}_{\mathrm{j}}} \mathrm{C}_{\mathrm{i}}
$$

$\mathrm{d}_{\mathrm{j}}$ (voting) represents the average difficulty parameter of the j-th knowledge point after the students' cooperative voting, $n_{i j}$ represents the number of students who gave the $\mathrm{j}$-th knowledge point i-level feedback response, and $\mathrm{N}_{\mathrm{j}}$ is the total number of students who evaluated the $\mathrm{j}$-th knowledge point.

Difficulty of adjusted knowledge points:

$\operatorname{Dj}($ turned $)=\mathrm{w} * \operatorname{dj}($ initial $+(1-\mathrm{w}) * \operatorname{dj}($ voting $)$

$\mathrm{d}_{\mathrm{j}}$ (turned) is the adjusted difficulty parameter based on the $j$-th knowledge point voted by the students, $d_{j}$ (initial) represents the initial difficulty of the ith course material given by the course expert, and $\mathrm{w}$ represents the initial difficulty of the first acquaintance as assessed by the expert.

K-means algorithm only assigns each data point to a category, and does not allow uncertainty in membership. The membership in the classification is expressed as the distance from the midpoint.

The squared error criterion is defined as follows:

$$
\mathrm{E}=\sum_{\mathrm{i}=1}^{\mathrm{k}} \sum_{\mathrm{p} \subseteq \mathrm{i}}\left|\mathrm{p}-\mathrm{m}_{\mathrm{i}}\right|^{2}=0
$$

Among them, $\mathrm{m}_{\mathrm{i}}$ is the center of cluster $\mathrm{i}, \mathrm{p}$ is the object in cluster $i$, and $c_{i}$ represents cluster $i$.

In the system model we designed, the student agent collects student information and builds a student model. Based on the data of learning ability and learning behavior in the student model, we use the K-means algorithm to gather students with similar attributes into families, so that Students in the same ethnic group have high similarities. We set the result of clustering to have a corresponding mapping relationship with the degree of difficulty of the course materials, so that it is convenient for the teacher agent to make personalized recommendations to similar groups.

\section{Experiment of Personalized Reform of Computer Education Based on Network Teaching Mode}

Since one of the purposes of the evaluation is to compare the advantages and disadvantages of personalized online teaching and traditional online teaching, when evaluating, we should set up a control group that adopts traditional online teaching for the experimental group that uses personalized online teaching. In terms of traditional online teaching, how much the effect of personalized online teaching improves is used as the evaluation criterion. After completing the study of the Internet theme of "Configuring the Computer", I obtained a lot of data through the questionnaire and evaluation scale. Due to space limitations, only part of the data is listed and explained here. The purpose of this experiment is to evaluate the NICAI system. The evaluation objectives are as follows: determine whether students can use the system to meet the requirements of the syllabus; determine whether the student model established by the system is reasonable; compare the personalized teaching system with the traditional online teaching system the pros and cons of the system; find out that the system is not good enough for improvement.

\section{Experimental Analysis of the Personalized Reform of Computer Education Based on the Network Teaching Mode}

\subsection{Comparison of Learning Evaluation}

Whether the NCICAI system can achieve the expected teaching effect must be tested by practice. Evaluation is an intermediary between knowledge and practice. The socalled education evaluation refers to the process of systematically collecting and analyzing information to make a judgment on the degree to which educational activities meet the expected needs in order to achieve the value-added education. Modern education evaluation advocates that education evaluation should take the degree to which educational activities meet the needs of society and individuals as the criterion of value judgment, and its ultimate goal is to achieve educational value appreciation. This exploratory learning is my first attempt in computer teaching. It is a turning point for me to accept the studentcentered teaching philosophy and gradually try after a long period of traditional teaching. Through the implementation of this online subject inquiry learning, students have gone through the entire process of inquiry 
and basically achieved our teaching goals. The most important thing is that most students have exerted their abilities in autonomy, cooperation, and inquiry, and some are organized Some of them are technical supporters. They learn from each other and cooperate with each other. In order to achieve a goal, the cooperation and interaction between each other has long-term significance for the development of students.

From the results of this personalized online teaching, there are some changes from traditional online teaching as shown in Table 1. Compared with traditional online teaching, the ratio of excellent to good in the evaluation of personalized online teaching has increased, and the ratio of medium to poor is reduced, and the effect of technology application has improved greatly, as shown in Figure 1.
However, the progress of individual students is not obvious. The main reason is the problems of emotional attitude and values. Some students withdraw when encountering difficulties, and some students are unwilling to share the results with their classmates.

Table1. Comparison of the two technology application learning evaluations

\begin{tabular}{|l|l|l|l|l|}
\hline & excellent & good & middle & $\begin{array}{l}\text { fall } \\
\text { short of }\end{array}$ \\
\hline $\begin{array}{l}\text { Personalized } \\
\text { network teaching }\end{array}$ & $34.2 \%$ & $41.7 \%$ & $18.6 \%$ & $5.5 \%$ \\
\hline $\begin{array}{l}\text { Traditional } \\
\text { network teaching }\end{array}$ & $20.7 \%$ & $25.6 \%$ & $42.9 \%$ & $10.8 \%$ \\
\hline
\end{tabular}

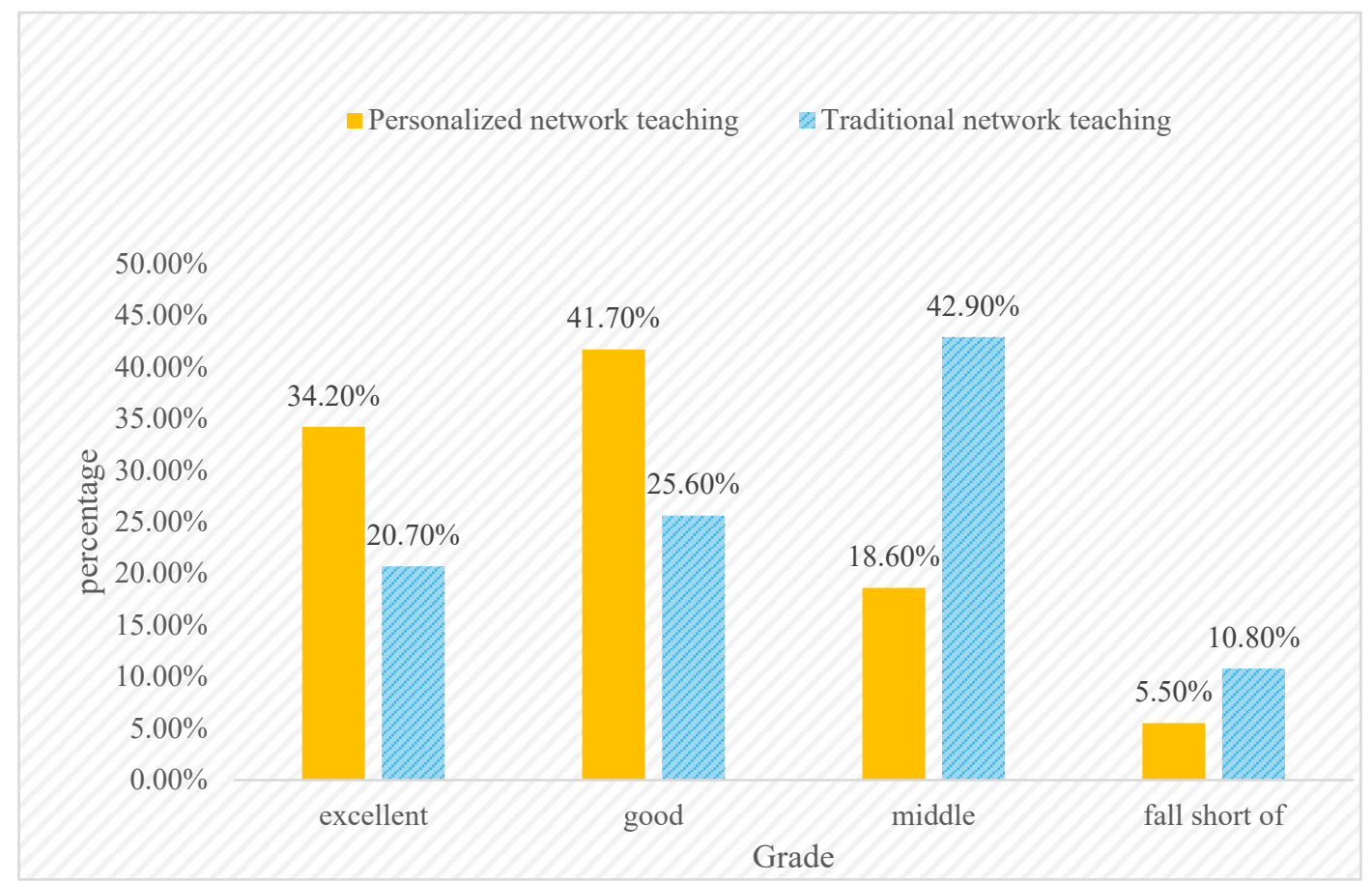

Figure 1. Comparison of the two technology application learning evaluations

Traditional collective teaching methods often adopt standardized and mechanical teaching plans, schedules and methods for all students, which leads to the failure of students' personality to be displayed and publicized. This phenomenon also exists in online education. Although the traditional online learning system provides students with richer learning resources, it still lacks the organic combination of interactive communication and teaching evaluation subsystems and learners' personalized learning. In the perspective of modern education, every student has unique talents, dispositions, preferences and advantages. The Internet makes learning no longer confined to classrooms and schools. Students no longer need to cut their feet to comply with unified teaching plans and standards. Instead, they can adopt unique learning approaches, learning methods and learning strategies according to their own characteristics and needs. Specifically, in order to effectively promote selfrealization and personality development, the basic requirements for the construction of a personalized online learning platform are: to provide learners with courseware, teaching videos, online assessments and forums with the individual differences of learners as the center and starting point. A variety of learning methods and feedback mechanisms allow learners to make personalized arrangements for learning content and progress according to their own situation.

\subsection{Comparison of Works Evaluation}

Individualized learning advocates putting students at the center of education. Therefore, the online teaching platform should be able to formulate teaching plans, schedules and personalized learning programs based on students' specific conditions, and adjust and improve teaching methods based on many factors. Building a personalized online teaching platform suitable for your school has a great role in promoting the development of the school. It not only promotes the realization of the college's application-oriented talent training goal, but also improves the utilization rate of teaching resources and 
saves the cost of the school. Alleviated the tight situation of college funding.

In personalized online teaching, more than $13 \%$ of the students' multimedia works have improved to excellent quality, as shown in Table 2. Through the re-practice of the personalized computer-assisted teaching system model, students' learning ability, cooperative spirit, and computer skills become stronger every time, and the learning effect is better every time. Initially learned the skills of how to learn and how to cooperate with others. This change is fully reflected in the evaluation of works as shown in Figure 2. The quality of teachers has also improved significantly. Great gains have been made in the ability to control the entire activity, the understanding of the activity, the understanding of the views of teachers and students, and the role of teachers.

Table2. Comparison of the two evaluations of multimedia works

\begin{tabular}{|l|l|l|l|l|}
\hline & excellent & good & middle & $\begin{array}{l}\text { fall } \\
\text { short of }\end{array}$ \\
\hline $\begin{array}{l}\text { Personalized } \\
\text { network teaching }\end{array}$ & $35.8 \%$ & $36.3 \%$ & $16.7 \%$ & $11.2 \%$ \\
\hline $\begin{array}{l}\text { Traditional } \\
\text { network teaching }\end{array}$ & $22.1 \%$ & $20.4 \%$ & $38.9 \%$ & $18.6 \%$ \\
\hline
\end{tabular}

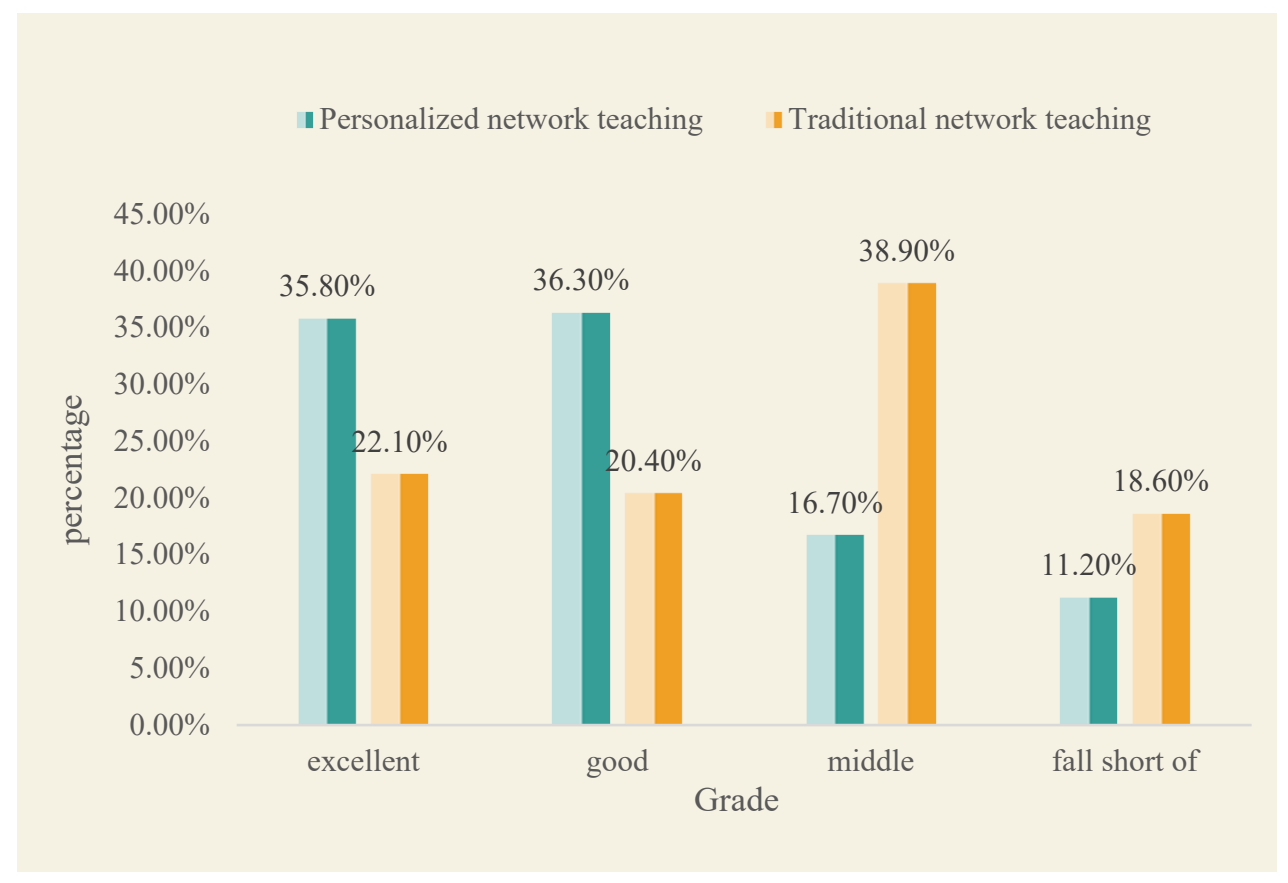

Figure 2. Comparison of the two evaluations of multimedia works

As shown in Figure 2, due to the support of school leaders, the strong cooperation of colleagues, and the two action arrangements are in line with the school's overall teaching plan, the two actions were implemented smoothly and basically achieved the expected goals proposed in this article.

As shown in Figure 2, students gave a high evaluation of the teaching effect of the personalized online teaching system, believing that the personalized online teaching system allows students to learn and train according to their actual level, and enhance their autonomy. At the same time, the teaching process is closely integrated with practice, which shortens the distance between theory and practice. Judging from the feedback from the students, the personalized goal of the personalized network teaching system has been basically achieved, with high flexibility and adaptability. The learning suggestions provided by the system reflect the differences in students' learning ability and learning experience, and have certain reference value for students to control and adjust their own personalized learning process. The students fully affirmed the content of the system, believing that the language is standardized, the amount of information is large, the coverage is wide, the examples provided are in line with the actual production, and the organization is clear.

\section{Conclusions}

This paper takes this school as an example to complete the realization of the network teaching platform based on the theory of individualized learning. Combining constructivist learning theory, autonomous learning theory, personalized learning theory, etc., the basic functions that a personalized online teaching platform needs to be realized are determined; secondly, the diagnosis of student learning and similar group division algorithms are added to the design of the platform. Students' learning and teachers' teaching put forward strategies, highlighting the individual characteristics of the teaching platform. A more comprehensive introduction to the practical development process of personalized learning mode in the context of the Internet, Internet of things and cloud computing. After a democratic investigation, a personalized network teaching and traditional network teaching platform were selected for experiments, and a scientific demonstration was carried out on the evaluation of students' learning and 
work. Through factor analysis of the data after students use the platform, it further proves the advantages of personalized online teaching. This experiment and survey have made a good practical demonstration of the investigation and reform of the practical application of the college's personalized learning mode.

\section{Fund}

supported by the Science Planning research funds of Nanchong City, Sichuan Province ," An Empirical Study on Personalized Learning Model Based on Online Teaching " (Project No: NC2020C172);

supported by the fundamental research funds of China West Normal University ," Research on an online social network dynamic community discovery method" (Project No: 19D042)

\section{References}

1. Wang N, Zhang Y . Application Status and Promotion Strategy of Integrated Network Teaching Platform- Taking Northwest A\&F University as an Example[J]. Asian Agricultural Research, 2019, 11(04):94-96.

2. Li H, Zhang H, Zhao Y . Design of Computer-aided Teaching Network Management System for College Physical Education[J]. Computer-Aided Design and Applications, 2021, 18(S4):152-162.

3. Huang Z , Liu Y . Research on Management Accounting Practice: A Network Teaching Model Guided by Practical Simulation[J]. Modern Economy, 2020, 11(1):89-95.

4. Shuo C, Xiao C. The construction of internet + piano intelligent network teaching system model[J]. Journal of Intelligent and Fuzzy Systems, 2019, 37(89):1-9.

5. Jia $X$. Agent-based Individual Network Teaching System for Modern History Outline of China[J]. International Journal of Emerging Technologies in Learning (iJET), 2018, 13(4):162.

6. Buxton, Gavin, A. Mathematical Modelling and Computer Simulations in Undergraduate Biology Education $[\mathrm{J}]$. Spreadsheets in Education (eJSiE), 2018, 10(3):3-3.

7. Gubina L V, Alekseeva T V, Strakhov O A. Analysis of some factors influencing the performance of college students: An example of Computer Science education[J]. The Education and science journal, 2020, 22(2):171-196.

8. Li H, Zhang H, Zhao Y . Design of Computer-aided Teaching Network Management System for College Physical Education[J]. Computer-Aided Design and Applications, 2021, 18(S4):152-162.

9. Mbise K S . The Use of Mobile Compilers for Learning Computer Programming in Higher Education Institutions: A Case of IAA and ATC[J]. International Journal of Scientific and Research Publications (IJSRP), 2020, 10(8):712-717.
10. Gorbunova I B , Plotnikov K Y . Music Computer Technologies in Education as a Tool for Implementing the Polymodality of Musical Perception[J]. Musical Art and Education, 2020, $8(1): 25-40$ 